\title{
A METAMORFOSE E A DESUMANIZAÇÃO DE GREGOR SAMSA
}

Lucas Cyrino

Submetido em 23 de maio de 2018.

Aceito para publicação em 03 de outubro de 2018.

Cadernos do IL, Porto Alegre, n. ${ }^{\circ}$ 57, novembro, p. 101-111

\section{POLÍTICA DE DIREITO AUTORAL}

Autores que publicam nesta revista concordam com os seguintes termos:

(a) Os autores mantêm os direitos autorais e concedem à revista o direito de primeira publicação, com o trabalho simultaneamente licenciado sob a Creative Commons Attribution License, permitindo o compartilhamento do trabalho com reconhecimento da autoria do trabalho e publicação inicial nesta revista.

(b) Os autores têm autorização para assumir contratos adicionais separadamente, para distribuição não exclusiva da versão do trabalho publicada nesta revista (ex.: publicar em repositório institucional ou como capítulo de livro), com reconhecimento de autoria e publicação inicial nesta revista.

(c) Os autores têm permissão e são estimulados a publicar e distribuir seu trabalho online (ex.: em repositórios institucionais ou na sua página pessoal) a qualquer ponto antes ou durante o processo editorial, já que isso pode gerar alterações produtivas, bem como aumentar o impacto e a citação do trabalho publicado.

(d) Os autores estão conscientes de que a revista não se responsabiliza pela solicitação ou pelo pagamento de direitos autorais referentes às imagens incorporadas ao artigo. A obtenção de autorização para a publicação de imagens, de autoria do próprio autor do artigo ou de terceiros, é de responsabilidade do autor. Por esta razão, para todos os artigos que contenham imagens, o autor deve ter uma autorização do uso da imagem, sem qualquer ônus financeiro para os Cadernos do IL.

\section{POLÍTICA DE ACESSO LIVRE}

Esta revista oferece acesso livre imediato ao seu conteúdo, seguindo o princípio de que disponibilizar gratuitamente o conhecimento científico ao público proporciona sua democratização.

http://seer.ufrgs.br/cadernosdoil/index

Quinta-feira, 22 de novembro de 2018. 


\title{
A METAMORFOSE E A DESUMANIZAÇÃO DE GREGOR SAMSA
}

\section{THE METAMORPHOSIS AND THE DEHUMANIZATION OF GREGOR SAMSA}

\author{
Lucas Cyrino $^{28}$
}

\begin{abstract}
RESUMO: Este artigo observa, na literatura, as implicações da metamorfose. Partindo do pressuposto que o estágio anterior à transmutação é o humano, buscamos em Benjamin (1992) e Benveniste (1991) uma concepção de linguagem que reconhece a posição superior do humano em relação aos demais seres e coisas da natureza, animada ou inanimada. A metamorfose, na medida em que faz com que o homem passe à condição física daqueles que antes eram a ele subordinados, termina por desumanizá-lo. Para tanto, observamos, inicialmente, como a metamorfose opera na literatura a partir do exemplo de dois mitos oriundos d'As metamorfoses, de Ovídio. Finalmente, debruçamo-nos a verificar de que maneira as condições da metamorfose estabelecidas em Ovídio são modificadas n'A metamorfose, de Franz Kafka.
\end{abstract}

PALAVRAS-CHAVE: Linguagem; Desumanização; Metamorfose; Franz Kafka.

ABSTRACT: This article observes the implications of the metamorphosis in literature. Assuming that the pre-transmutation stage is human, we seek in Benjamin (1992) and Benveniste (1991) a conception of language that recognizes the superior position of the human in relation to other beings and things of nature, animated or inanimate. The metamorphosis, as it makes man go to the physical condition of those who were before subordinated by him, ends up dehumanizing him. For this, we first observe how metamorphosis operates in literature from the example of two myths originating from The metamorphosis, by Ovid. Finally, we examine how the conditions of metamorphosis established in Ovid are modified in Franz Kafka's Metamorphosis.

KEYWORDS: Language. Dehumanization. Metamorphosis. Franz Kafka.

\section{A linguagem do homem}

Em ensaio de 1916, intitulado "Sobre a linguagem em geral e sobre a linguagem humana", Walter Benjamin (1992) explora uma compreensão acerca da linguagem que a reconhece não apenas como o centro da comunicação dos homens, mas também analisa a parcela da linguagem atrelada às coisas - aos objetos e aos animais, por exemplo - que estão presentes na natureza e que dependem do homem para, de alguma forma, serem comunicadas. Como todos os seres e todas as coisas participam da linguagem para expressar-se e comunicar-se, é por meio dela que se expressa o que Benjamin chama de conteúdo espiritual: "não há acontecimento ou coisa, seja na natureza animada, seja na inanimada que, de certa forma, não participe na linguagem, porque a todos é essencial a comunicação do seu conteúdo espiritual” (1992, p. 177). Esse conteúdo, portanto, pode ser o cerne da própria mensagem - ou o signo, na medida em que agrega fatores significantes, interpretáveis a partir do código da linguagem usado pelo emissor no ato de comunicação, e significados, na realização do discurso seja tal mensagem expressa verbalmente ou não.

\footnotetext{
${ }^{28}$ Doutorando em Letras na UFRGS, é Mestre em Estudos de Literatura pela mesma universidade, atuando na linha de pesquisa Literatura, Sociedade e História da Literatura. E-mail: laccyrino@gmail.com.
} 
A comunicação desse conteúdo espiritual depende desses fatores linguísticos e extralinguísticos (ou do signo, na analogia que propomos), mas principalmente do eixo significante no processo, reconhecido como conteúdo linguístico. Intrinsecamente ligados ambos os conteúdos, linguístico e espiritual, aquilo que chamamos de signo, no termo saussureano, é chamado por Benjamin de conteúdo intelectual, cuja expressão só se realiza por meio da linguagem. Esta, por sua vez,

significa o princípio orientado para a comunicação de conteúdos intelectuais. [...] Numa palavra: toda e qualquer comunicação de conteúdos é linguagem, sendo a comunicação através da palavra apenas um caso particular, subjacente a conteúdos humanos ou que nele se baseiam. (BENJAMIN, 1992, p. 177)

Nessa direção, a linguagem permite comunicação à essência espiritual porque une o eixo que lhe dá sentido (conteúdo espiritual) com o eixo que o nomeia (conteúdo linguístico). Isso talvez baste para identificar que a essência linguística, diferentemente da essência espiritual, pode estar relacionada à língua, manifestação própria do homem; contudo, "a essência espiritual que se transmite na linguagem não é a língua em si, mas algo que dela deve ser diferenciado" (BENJAMIN, 1992, p. 178). A essência espiritual está presente no homem, mas também em todas as outras coisas e seres da natureza que, participantes na linguagem, possuem alguma significação.

Diferente das demais espécies animais, a linguagem do ser humano, que se realiza inicialmente com base na oralidade, faz com que seu conteúdo espiritual seja expresso na sua própria linguagem, na sua própria comunicação. Dominando essa capacidade comunicativa com exclusividade entre os outros seres da natureza (e entre todas as coisas), o homem se coloca em posição hierárquica imediatamente superior e absoluta, pertencendo a ele o domínio sobre a comunicação e sobre os "nomes" que ele mesmo atribui aos outros seres, projeções semiológicas ou simbólicas de significados e significantes (cf. BENJAMIN, 1992, p. 182). Ainda que todos os seres participem na linguagem pela comunicação de seu conteúdo espiritual, somente o homem ativa essa comunicação por meio dela.

Se a linguagem está na essência do ser humano, significa que ela é o ponto que estabelece a mediação entre ele e o mundo à sua volta, entre ele e seus pares, entre ele e os outros seres da natureza. A linguagem também está na essência dos outros seres, mas a eles falta a parcela "significante" que lhes permita realizar-se na comunicação de maneira autônoma, independente. Há, portanto, uma diferença entre a linguagem do homem e a linguagem das coisas, porque, se considerarmos que a base da comunicação parte da língua, que está relacionada à comunicação humana, os outros seres são colocados em posição imediatamente dependente e subordinada em relação ao homem, posto que incapazes de comunicar suas essências espirituais de modo autônomo.

Essa subordinação ocorre porque, de acordo com Benjamin,

o homem comunica a sua própria essência espiritual na sua linguagem. Mas a linguagem do homem fala por palavras. O homem comunica, pois, a sua própria essência espiritual (na medida em que é comunicável), denominando todas as outras coisas. [...] A essência linguística do homem é, pois, o fato de ele designar as coisas. (1992, p. 180, grifos do autor)

Se o homem nomeia e, ato contínuo, estabelece domínio hierárquico sobre as coisas, é por meio da palavra que essa linguagem se materializa. Antes de ser escrita, a palavra é oralizada, expressando a comunicação por meio do aparelho fonador estritamente particular à espécie humana. Logo, se a linguagem das coisas - e das 
demais espécies animais - não se realiza pela fala, então o seu conteúdo espiritual fica preso ao plano do não-comunicável; sua expressão - e sentido - só se realiza quando dotada de algum significado atribuído pelo homem.

Em direção semelhante, Émile Benveniste observa que "é na linguagem e pela linguagem que o homem se constitui como sujeito" (1991, p. 286, grifo do autor). À primeira vista, a afirmativa de Benveniste corrobora que a língua constitui o homem, e isso por si só já seria óbvio o suficiente se considerarmos, tal como Benjamin, que a capacidade de comunicar-se pela língua é única da humanidade. Porém, levando em conta que o homem comunica a sua própria essência na medida em que se comunica pela linguagem, é o ato de comunicar-se com o outro (um "tu", em termos de Benveniste) que se constitui a sua essência, que o constitui como sujeito. Mais que isso: a essência espiritual do homem concebe a sua existência não apenas na medida em que ele se comunica com outros homens, mas também à medida que nomeia o mundo ao seu redor, porque é desse processo de troca de experiências - ou troca de subjetividades, para incorrer na terminologia proposta por Benveniste (1991, p. 289) - que o homem amadurece e se constitui como sujeito, como pessoa atuante no mundo em que vive: "a instalação da 'subjetividade' na linguagem cria na linguagem e, acreditamos, igualmente fora da linguagem, a categoria da pessoa" (BENVENISTE, 1991, p. 290).

É também por meio da linguagem que o homem comunica a arte. Dotada de conteúdo simbólico e espiritual, a arte é capaz de unir ou separar o homem e a natureza, o homem e os outros homens, o homem e os animais, o homem e as coisas; mas volta-se sempre ao homem, já que é por sua ação que o seu sentido se materializa em linguagem, seja ela verbal, não verbal ou performática. No que diz respeito à literatura, criação humana, essa materialização se dá, via de regra, na superfície do texto, da palavra-signo expressa por meio do código escrito, mesmo quando esse texto é oriundo da oralidade. $\mathrm{O}$ percurso que se estabelece na relação entre o homem e a arte, nessa medida, influencia direta e intimamente a constituição do homem como sujeito, porque a experiência estética pressuposta pela arte acaba por humanizá-lo ainda mais, acaba por permitir que este homem de alguma forma "amadureça" o seu modo de interagir com o mundo.

Se a arte, como uma das manifestações da linguagem humana, propõe a formação (ou o desenvolvimento) de um sujeito autônomo, pensante e mais humano, e se além da arte a própria comunicação baseada na linguagem humana também oferece algum tipo de superioridade ao homem em relação aos outros seres e coisas, dada a sua particularidade no trato com a língua, então o homem ocupa uma posição não apenas privilegiada, mas aparentemente intocável: o homem é o senhor da natureza. O que pode abalar essa relação, o que pode fazer com que ela se inverta? O que pode fazer com que o homem, do alto de sua superioridade, termine desumanizado, fazendo parte das classes que antes eram a ele subordinadas?

\section{A metamorfose como punição}

Se a superioridade do homem em relação aos demais seres e coisas se realiza na linguagem, talvez seja válido considerar que essa hierarquia se configura inerente às suas diversas manifestações, inclusive a artístico-literária - o que impele, imediatamente, uma resposta negativa à pergunta formulada anteriormente: nada, no mundo real, pode fazer com que o homem seja subordinado às coisas e seres por ele nomeados. Paradoxalmente, porém, à medida que a arte (como a literatura) venha a pressupor um contexto ficcional, aí, sim, torna-se possível ao homem descer de seu 
posto de superioridade e autoridade e acabar ao mesmo nível das coisas que antes nomeava - privado, portanto, da comunicação baseada na linguagem.

O que pretendemos defender, inicialmente, é que, no campo da ficção literária, a perda da comunicação pode ser o produto imediato de uma metamorfose no homem. Se esse tipo de transformação exige transmutação corpórea, é fato que o homem deixa de lado a sua aparência humana - e, com ela, deixa também a linguagem, posto que esta não seja partilhada por nenhuma outra espécie ou coisa. Logo, a perda da capacidade comunicativa representa a perda da própria humanidade, em favor de uma vida que continua - ou se inicia - em uma nova forma, seja ela animal ou vegetal. Nesses casos, a natureza da essência espiritual de cada coisa provavelmente se converte em outra, posto que a capacidade de comunicá-la, na direção de constituir uma essência intelectual, agora depende unicamente da percepção e da ação de outro ser humano.

A primeira indicação nessa direção talvez possa ser observada na mitologia, de onde emerge a discussão sobre a metamorfose pretendida neste estudo. Em As metamorfoses, de Ovídio, mais precisamente no mito fundador "Palas e Aracne", por exemplo, Tritônia decide castigar Aracne porque esta supostamente se nega a aceitar a sua superioridade na arte tecelã; sentindo-se desafiada e ofendida diante da ideia de ter sido instruída por Palas, a moça propõe uma competição a partir da qual se chegaria à autora da arte "superior". Ocorre que a peça de Aracne desponta em beleza, de modo que, coberta de inveja e mágoa, Tritônia rasga sua tela e golpeia-lhe a testa. Diante da afronta, Aracne se enforca, mas tem a própria morte entrecortada pela ação de Palas que, não contente com a situação, acaba por verdadeiramente puni-la, metamorfoseando-a em uma aranha:

\footnotetext{
"Pode viver atrevida, mas pendurada. E, para que não acalentes esperanças no futuro, determino que o mesmo castigo seja aplicado contra a tua estirpe e teus mais afastados descendentes". Depois disso, ao partir, espargiu o suco de uma planta infernal, e, mal Aracne foi tocada pelo filtro maldito, caíram-lhe os cabelos, o nariz e as orelhas; a cabeça tornou-se minúscula e o corpo se encolheu proporcionalmente; nas ilhargas se prendem dedos em lugar de pernas; o resto é o ventre, de onde, no entanto, deixa escapar o fio, e, tornada aranha, continua a tecer, como antigamente. (OVÍDIO, 1983, p. 145)
}

A cólera de Tritônia não aparece de graça: a superioridade que tentava demarcar artisticamente em relação a Aracne, embora carregada de inveja, é provavelmente transposta da origem social da jovem tecelã que, vinda da plebe, conquistara fama por meio da arte. Quando se vê ameaçada, a tendência de Tritônia é subjugar Aracne, que acaba transformada em um inseto - a aranha, daí o caráter fundador do mito - quase "monstruoso", já que, pelo que se percebe na narração, a transmutação sofrida pelo seu corpo faz com que haja necessariamente uma mudança de reino animal. Em uma palavra, Aracne perde sua humanidade, e perde, com ela (sob o jugo da superioridade exercida tanto por Tritônia, quanto por Palas, que em "piedade" a metamorfoseia), a posição ainda superior que exercia em relação às outras espécies animais, posto que perde a capacidade de realizar-se por meio da linguagem, de constituir-se como sujeito - perde, enfim, a capacidade de se comunicar.

Situação não muito distinta acontece com Dafne no mito homônimo, também oriundo d'As metamorfoses, de Ovídio. Ela, ninfa filha do Peneu (divindade que, na mitologia, assumia a forma de um rio), acaba por ser envolvida em uma situação cuja culpa, se lhe fosse devida, talvez estivesse relacionada à sua beleza. Ocorre que, logo após Apolo ter derrotado a grande serpente Píton, este vê Cupido manipulando o seu arco e corda. Movido pelo orgulho, Apolo insulta-o: "contenta-te, com o teu facho, de seguires a pista de não sei que amores, e não aspires aos louvores que mereço". Cupido, 
porém, responde à altura: "Que o teu arco atinja tudo, ó Febo. O meu te atingirá. Tanto quanto todos os seres vivos são superados por um deus, a tua glória é inferior à minha" (OVÍDIO, 1983, p. 27).

O filho de Vênus, então, prepara duas setas distintas, uma capaz de afastar o amor e outra de aproximá-lo. A primeira seta é direcionada a Apolo; a segunda é direcionada a Dafne, e entre ambos se inicia uma espécie de caça: a ninfa, cuja beleza fazia-se notar, foge em disparada do seu suposto pretendente. Quando já não aguenta mais correr, suplica a Peneu: "Socorre-me, meu pai! Se vós, os rios, tendes um poder divino, muda a minha aparência, culpada de muito agradar!". Imediatamente começa a metamorfose de Dafne, indicando resposta positiva por parte de seu pai:

\begin{abstract}
Mal acabara a súplica, um pesado torpor lhe invade os membros; seu peito delicado se reveste de uma fina casca, os cabelos se transformam em folhas, os braços em ramos; os pés que ainda há pouco corriam tão rápidos, são raízes ao chão presas agora, o rosto desaparece na fronte. Somente o seu encanto permanece. Febo ainda a ama e, pondo a mão no tronco, sente o coração que continua a bater sob a nova casca. Abraçando os ramos, como se fossem membros, cobre a madeira de beijos, mas a madeira se furta aos seus beijos. (OVÍDIO, 1983, p. 29)
\end{abstract}

A metamorfose de Dafne difere substancialmente daquela sofrida por Aracne porque agora se trata de uma súplica pessoal, enquanto no outro caso tratava-se de uma punição direta - ou seja, Aracne restava metamorfoseada em aranha como resultado de suas ações. A situação de Dafne, porém, não afasta completamente a possibilidade da punição, colocando-a em segundo plano. Ciente de sua beleza, Dafne acredita que é essa característica que faz com que Apolo a persiga, quando a punição, que partira do Cupido, estava dirigida a ele: amando sem reciprocidade, ele é quem deveria sofrer por cortejá-la sem conseguir resposta.

No auge do desespero, porém, a ninfa suplica que seja transfigurada, mas não explicita que seu desejo fosse ser transformada em uma árvore, ou outra espécie animal - sua fala é bastante clara: "muda a minha aparência, culpada de muito agradar!". Dafne, quando metamorfoseada em loureiro, deixa para trás a sua humanidade, mas não deixa a sua essência, posto que continua bela ("Somente o seu encanto permanece"). A noção de "aparência", aparentemente, é levada ao caso extremo de fazê-la passar por um processo de transmutação, convertendo-a em outro tipo de ser vivo, por sua vez pertencente a um reino distinto da natureza.

As metamorfoses de Aracne e Dafne, embora possuam caráter punitivo, permitem que se edifiquem na literatura os pilares característicos dessa mudança corpórea. Em certa medida, o conteúdo espiritual que se realiza no ser humano por sua própria expressão perde validade quando sofre uma transmutação, pois a partir da metamorfose, ocupando um novo corpo, integrando uma nova categoria animal ou vegetal, esse ser deixa de lado seu caráter "humano" para receber, finalmente, uma nova "personificação", da qual resulta a perda da linguagem humana - ato contínuo, a irrealização autônoma e soberana do conteúdo espiritual expresso em linguagem. Notase o fato em Aracne quando se percebe que a metamorfose é o fim único de sua existência, imediatamente inferior aos seres humanos (posto que se torna um inseto) e desprovida de comunicação, sem falar na condenação estendida à sua estirpe. Com Dafne, por sua vez, a punição não segue caminho muito diferente: mesmo que mantenha preservado o seu encanto (a sua essência espiritual), quando transformada em árvore a ninfa acaba privada permanentemente da comunicação humana. 


\section{A metamorfose de Gregor Samsa}

Com Kafka, a metamorfose ocupa um novo patamar na arte literária, no qual o mito passa a ser não mais formador, mas transformador. Se antes sabíamos o contexto e/ou a razão pela qual Aracne e Dafne acabaram transmutadas, agora não sabemos que condições e ações fizeram com que Gregor Samsa acordasse metamorfoseado. Além disso, não se pode afirmar que se trata de uma ação punitiva, dado que a metamorfose não é o fim da realização de sua linguagem, mas o início de uma nova perspectiva:

\footnotetext{
Quando certa manhã Gregor Samsa acordou de sonhos intranquilos, encontrou-se em sua cama metamorfoseado num inseto monstruoso. Estava deitado sobre suas costas duras como couraça e, ao levantar um pouco a cabeça, viu seu ventre abaulado, marrom, dividido por nervuras arqueadas [...]. Suas numerosas pernas, lastimavelmente finas em comparação com o volume do resto do corpo, tremulavam desamparadas diante dos seus olhos.

- $\mathrm{O}$ que aconteceu comigo? - pensou.

Não era um sonho. [...] (KAFKA, 1997, p. 7)
}

A metamorfose de Gregor leva a um novo reconhecimento do ambiente, a uma nova perspectiva em relação ao seu modo de vida, afetando a sua família (que, gradativamente, trata-o cada vez mais como animal, como inseto, ao ponto de pretender jogá-lo à rua), mas também encaminha a desumanização que lhe é inerente à manutenção do seu conteúdo espiritual. Kafka mantém a capacidade comunicativa de Gregor e de sua essência porque há nele a manutenção de alguma linguagem, embora seja ininteligível às demais personagens. Essa manutenção é revelada pelo narrador que, quando não utilizando o discurso indireto livre, traz a fala de Gregor seguida ou precedida do verbo "pensar" - como na citação anterior, que termina com "O que aconteceu comigo? - pensou". O ato de pensar não é realizar-se na língua, justamente porque não há interação com um outro - com um “tu”, no termo de Benveniste - com o qual se choquem identidades e construções de sujeito na direção de promover alguma intersubjetividade. Dado que antes da metamorfose Gregor tenha tido a experiência do humano, na situação à qual Gregor se resume, agora, sua subjetividade fica reduzida a si mesmo, ao alcance apenas da consciência do narrador que não interage com ele.

Logo, a situação de Gregor é de difícil resolução. À diferença do que acontecia com Aracne, sua transformação não funda uma nova espécie que perdure ao longo da história da humanidade; além disso - e o mais importante -, Gregor de alguma forma persevera na manutenção da sua essência espiritual, que é, muito provavelmente, a mesma de quando tinha uma forma física humana. Ocorre, no entanto, que agora ele já não pode se comunicar com outros seres humanos, porque não possui mais o domínio da linguagem - nem mesmo a aparelhagem orgânica necessária, particular apenas à espécie humana.

É, contudo, a comunicação acessível apenas ao leitor e ao narrador que coloca Gregor Samsa em uma nova perspectiva em relação à metamorfose, revista e refundada por Kafka em 1912. Com Gregor "metamorfoseado num inseto monstruoso", a metamorfose ainda lhe retira a humanidade e coloca-o numa posição hierárquica e organicamente inferior à espécie humana. Entretanto, apesar da sua "nova personificação" impedir sua realização na linguagem com e entre os demais seres humanos, a condição da metamorfose não impede que seu conteúdo espiritual se realize e, à revelia do que até então se estabelecia para as metamorfoses na literatura, seja acessível a um outro - neste caso, o leitor. 


\section{A chancela da desumanização}

Gregor não é mais um ser humano, já que se encontra metamorfoseado em um inseto. Conserva, contudo, a essência espiritual de quando dispunha da forma humana, como se restasse nele uma parcela de humanidade, mesmo que enfraquecida pela situação adversa. É provável que para si, mesmo sentindo-se em um corpo estranho, Gregor ainda conservasse uma consciência de mundo que o colocasse como humano. No entanto, a partir da percepção e do julgamento daqueles que o rodeiam, a noção de Gregor em relação a si também muda - e a chave dessa mudança de perspectiva está basicamente na linguagem.

Ainda no início da novela, quando Gregor fica agitado ao perceber que o tempo passa e que, às sete horas, já perdera o trem das cinco que o levaria ao trabalho, sua mãe bate na porta do quarto para chamá-lo - é a primeira tentativa de interação de alguém com Gregor, e, notemos, trata-se de uma interação baseada na linguagem humana. Quando percebe a voz da mãe, porém, ele ao mesmo tempo se surpreende com a sua própria voz:

\footnotetext{
Gregor se assustou quando ouviu sua própria voz responder, era inconfundivelmente a voz antiga, mas nela se imiscuía, como se viesse de baixo, um pipilar irreprimível e doloroso, que só no primeiro momento mantinha literal a clareza das palavras, para destruí-las de tal forma quando acabavam de soar que a pessoa não sabia se havia escutado direito. Gregor quisera responder em minúcia e explicar tudo, mas nestas circunstâncias se limitou a dizer:

- Sim, sim, obrigado, mãe, já vou me levantar. (KAFKA, 1997, p. 11)
}

A descrição da voz de Gregor anuncia que o som por ele emitido não é exatamente humano. Ciente ou não completamente ciente de que seu corpo passara por uma metamorfose, Gregor, à primeira vista, começa a perceber que a mudança também se estende à sua voz - embora ainda não aceite completamente - de modo que essa transformação logo se converterá em uma ruptura do processo comunicativo. Tanto sucede assim que a sequência, tratando da percepção dos familiares externos ao quarto em relação à voz de Gregor, fará notar que algo não corre bem com o protagonista: todos batem à sua porta e chamam pelo seu nome, enquanto ele, ciente de que há algum problema, limita-se a falar "através da pronúncia mais cuidadosa e da introdução de longas pausas entre as palavras", num esforço "[...] para retirar à sua voz tudo que chamasse a atenção" (KAFKA, 1997, p. 11-12).

Uma vez que Gregor permanece no quarto, sua agitação é toda voltada a concentrar-se em uma maneira de finalmente levantar da cama. Ele empreende uma movimentação lenta enquanto seus pais, da sala, continuam chamando-o; em meio a isso, Gregor chega a imaginar como seria mais fácil se conseguisse a ajuda de duas pessoas fortes, como o pai e a empregada, que o poriam em pé e ele finalmente poderia dar cabo daquela situação. Gregor sai do devaneio quando ouve alguém bater à porta que dá para a rua - trata-se do gerente da firma onde trabalha, vindo em pessoa verificar o motivo do atraso.

A dinâmica da cena é rápida ao cruzar a reflexão de Gregor, revelada pelo discurso do narrador, com a ação desencadeada. Para o primeiro caso, a denúncia sobre o sistema é levantada de imediato em relação à firma onde o protagonista trabalha: "Por que Gregor estava condenado a servir numa firma em que à mínima omissão se levantava logo a máxima suspeita?" (KAFKA, 1997, p. 16). A agitação dos pensamentos faz com que Gregor tome a brusca decisão de sair da cama a todo custo, jogando o corpo ao chão. O barulho retumba na sala, chamando a atenção do gerente 
recém-chegado, de modo que tanto o pai quanto a irmã de Gregor, um por cada lado do quarto, tentam avisá-lo para que saia do quarto.

A mãe é quem intercede pelo filho, anunciando que algo deveria ter acontecido. Como Gregor continua no quarto e suas respostas aos chamados são aparentemente inaudíveis ou ininteligíveis aos demais, o gerente acaba revelando insatisfação em relação ao trabalho de Gregor e seu suposto "capricho" por não ir ao trabalho, insinuando que ele possa ter roubado dinheiro da firma em transações financeiras recentes. A denúncia tira o protagonista do controle:

\begin{abstract}
- Mas, senhor gerente - exclamou Gregor fora de si, esquecendo tudo o mais na excitação -, eu abro já, num instante. Um ligeiro mal-estar, um acesso de tontura, impediram-me de me levantar. Ainda estou deitado na cama. Mas agora me sinto novamente bem-disposto. Já estou saindo da cama. Só um instantezinho de paciência! As coisas ainda não vão tão bem como eu pensava. Mas já estou bem. Como é que uma coisa assim pode acometer um homem? Ainda ontem à noite estava tudo bem comigo, meus pais sabem disso, ou melhor: já ontem à noite eu tive um pequeno prenúncio. Eles deviam ter notado isso em mim. Por que não comuniquei à firma? Mas sempre se pensa que se vai superar a doença sem ficar em casa. Senhor gerente, poupe meus pais! Não há motivo para censuras que agora o senhor me faz; também não me disseram uma palavra a esse respeito. Talvez o senhor não tenha lido os últimos pedidos que eu remeti. Aliás, ainda vou viajar com o trem das oito, as horas de repouso me fortaleceram. Não se detenha mais, senhor gerente; logo mais estarei pessoalmente na firma: tenha a bondade de dizer isso e de apresentar minhas recomendações ao senhor chefe. (KAFKA, 1997, p. 20)
\end{abstract}

De fato, a fala de Gregor revela a excitação por ele depreendida, que resulta no esforço desesperador para mover-se pelo quarto e pôr-se, enfim, de pé. Contudo, o início do parágrafo que revela essa ação, que é imediatamente o posterior à citação acima, alerta que "Gregor expelia tudo às pressas, mal sabendo o que falava" (KAFKA, 1997, p. 20-21). A comunicação de Gregor com os demais encontra, por fim, um obstáculo, posto que não se realiza completamente. É claro que a expressão "mal sabendo o que falava" está relacionada ao fato de ele falar às pressas, em meio à agitação; ouvida pelos outros, no entanto, essa expressão se converte em incompreensão, principalmente porque, para eles, o que Gregor fala não é inteligível:

- Entenderam uma única palavra? - perguntou o gerente aos pais. - Será que ele não nos está fazendo de bobos?

- Pelo amor de Deus! - exclamou a mãe já em lágrimas. - Talvez ele esteja seriamente doente e nós o atormentamos. Grete! Grete! - gritou então.

- Mamãe? - bradou a irmã do outro lado.

Elas se comunicavam através do quarto de Gregor.

- Você precisa ir imediatamente ao médico. Gregor está doente. Vá correndo ao médico. Você ouviu Gregor falar, agora?

- Era uma voz de animal - disse o gerente, em voz sensivelmente mais baixa, comparada com os gritos da mãe. (KAFKA, 1997, p. 21-22)

A situação subsequente irá revelar o primeiro contato visual da família e do gerente com Gregor metamorfoseado, em meio a uma de suas raras saídas do quarto em direção à sala. Ele, ainda nesse ponto, tenta relacionar-se com os demais por meio de algum resquício de humanidade, alçada por sua responsabilidade junto ao trabalho principalmente levando em conta que a família depende de Gregor economicamente. É possível, nesse ponto, que Gregor ainda se sinta um pouco humano porque conserva, na sua nova forma animal, a essência espiritual de quando possuía forma humana. 
Essa essência torna-se passível de compreensão porque, graças à voz do narrador, é possível saber os pensamentos de Gregor, ou ainda aquilo que ele tenta expressar como mensagem aos demais. A comunicação, porém, não se realiza, posto que a subjetividade de Gregor não é posta em contato com a subjetividade dos outros exceto pela repulsa que passa a ser praticada por todos, dado o andamento da narrativa que conduzirá à ideia, imposta no seio da família pouco antes da morte do protagonista, de que deveriam expulsá-lo de casa.

Se Gregor Samsa deixa de ser humano, por outro lado conserva algo da sua essência espiritual, que permanece inalterada. A desumanização do personagem acaba chancelada pelo comportamento que passam a exercer aqueles que o rodeiam, fruto imediato não apenas da metamorfose, mas da ruptura do processo comunicativo que ela impõe a todos os envolvidos. Não é possível comunicar-se com um ser não humano, porque, obviamente, somente a espécie humana é capaz de falar, de expressar-se pela linguagem e, assim, trazer à tona a sua essência espiritual, realizar-se na própria linguagem. Gregor realiza-se apenas em pensamento, de modo que, aos olhos dos outros, ele resume-se à nova espécie animal (o "inseto monstruoso" em que se metamorfoseia). Posto que o homem, detentor da linguagem, é superior a todos os outros seres e coisas, a reação dos familiares e das demais pessoas em relação a Gregor não poderia ser diferente: não poderia deixar de envolver uma parcela de repulsa, mas principalmente superioridade.

\section{Considerações finais}

Gregor acaba transfigurado em um inseto do qual se sabe pouco além do adjetivo "monstruoso", da aparência e do tamanho; não se sabe a qual espécie esse inseto pertence, noção que se supõe saber no momento anterior à metamorfose, posto que Gregor fosse, obviamente, humano. Dado que o protagonista não é apresentado em momento algum na sua forma humana, a metamorfose, aqui, vai no caminho contrário daquele traçado por Aracne e Dafne, por exemplo. No caso delas, a transmutação era o resultado de ações desencadeadas por elas ou por pessoas próximas, afetando suas vidas e transformando-as perpetuamente em seres não humanos, dos reinos animal ou vegetal, cuja ruptura comunicativa não está estabelecida apenas no fato de não poderem mais se comunicar com outros humanos, mas sim no fato de absolutamente não comunicarem, de maneira autônoma (nem por pensamento, nem pela voz do narrador), qualquer sombra de sua essência espiritual anteriormente humana.

Em Kafka, a metamorfose não serve apenas para fundar uma explicação sobre algo, como acontecia com Aracne ou com Dafne, mas para abrir a chaga do inexplicável frente às relações interpessoais. Gregor mantém a sua essência espiritual humana na sua nova forma, e mesmo perdendo a capacidade da linguagem, ainda comunica essa essência por meio do pensamento (dado a saber pelo narrador). Dessa forma, Kafka estabelece, possivelmente, um novo capítulo na condição da metamorfose, já não limitadora da condição comunicativa da linguagem, da expressão e realização do conteúdo espiritual dos seres; afinal, não fosse a expressão íntima de Gregor a respeito de sua condição, traduzida pelo narrador e acessível a quem o lê, talvez sobrasse pouco à explicação da grandeza da obra kafkiana.

\section{REFERENCIAS}


BENJAMIN, W. Sobre a linguagem em geral e sobre a linguagem humana. Tradução de Maria Luz Moita. In: d'Água Editores, 1992. p. 177-196.

BENVENISTE, Émile. Da subjetividade na linguagem. In: . Problemas de linguística geral I. Tradução de Maria da Glória Novack e Maria Luiza Neri. Revisão de Isaac Nicolau Salum. 3. ed. Campinas: Pontes; Editora da Universidade Estadual de Campinas, 1991. p. 284-293.

KAFKA, Franz. A metamorfose. Tradução de Modesto Carone. São Paulo: Companhia das Letras, 1997.

OVÍDIO. As metamorfoses. Tradução de David Gomes Jardim Junior. Rio de Janeiro: Editora Tecnoprint, 1983. 